\title{
Inlet Turbulence and Length Scale Measurements in a Large Scale Transonic Turbine Cascade
}

\author{
Douglas Thurman ${ }^{1}$ \\ Army Research Laboratory, Cleveland, OH, 44135 \\ Ashlie Flegel ${ }^{2}$ \\ NASA Glenn Research Center, Cleveland, OH, 44135 \\ Paul Giel ${ }^{3}$ \\ Vantage Partners LLC, Cleveland, OH 44135
}

\begin{abstract}
Constant temperature hotwire anemometry data were acquired to determine the inlet turbulence conditions of a transonic turbine blade linear cascade. Flow conditions and angles were investigated that corresponded to the take-off and cruise conditions of the Variable Speed Power Turbine (VSPT) project and to an Energy Efficient Engine (EEE) scaled rotor blade tip section. Mean and turbulent flowfield measurements including intensity, length scale, turbulence decay, and power spectra were determined for high and low turbulence intensity flows at various Reynolds numbers and spanwise locations. The experimental data will be useful for establishing the inlet boundary conditions needed to validate turbulence models in CFD codes.
\end{abstract}

\section{Nomenclature}

$C_{x} \quad=$ blade axial chord [inch]

$E \quad=$ energy spectrum $\left[\mathrm{ft}^{2} / \mathrm{s}\right]$

$E_{1} \quad=$ energy spectrum function, $E_{1}=U E / 2 \pi\left[\mathrm{ft}^{3} / \mathrm{s}^{2}\right]$

$f \quad=$ frequency $[\mathrm{Hz}]$

$k=$ turbulence kinetic energy $\left[\mathrm{lb}_{\mathrm{m}} / \mathrm{ft} / \mathrm{s}^{2}\right]$

$k_{l} \quad=$ wave number, $k_{l}=2 \pi f / U\left[\mathrm{ft}^{-1}\right]$

$p \quad=$ blade pitch, $p=5.119$ [inch]

Re $\quad=$ inlet Reynolds number, $R e=\rho U c / \mu$

$s \quad=$ blade span, $s=6.000$ [inch]

$\mathrm{Tu}=$ turbulence intensity $=\bar{u} / U$

$\Delta T u=T u_{\text {upstream }}-T u_{\text {station } 0}$

$U \quad=$ velocity component in streamwise direction $[\mathrm{ft} / \mathrm{s}]$

$U_{\infty} \quad=$ tunnel freestream velocity $[\mathrm{ft} / \mathrm{s}]$

$U_{\text {avg }}=$ averaged instantaneous velocity from hotwire $[\mathrm{ft} / \mathrm{s}]$

$\bar{u}, U_{r m s}=$ fluctuations in streamwise velocity $U[\mathrm{ft} / \mathrm{s}]$

$X, Y=$ tunnel coordinate axes relative to blade row

$z=$ spanwise location relative to tunnel endwall [inch]

$\beta=$ inlet flow angle relative to axial $[\mathrm{deg}]$

$\delta_{99}=$ inlet boundary layer thickness at survey plane Station 0 [inch]

$\Lambda=$ integral length scale [inch]

$\lambda \quad=$ dissipation length scale [inch]

\footnotetext{
${ }^{1}$ Aerospace Research Engineer, Turbomachinery and Heat Transfer Branch, 21000 Brookpark Rd., Mail Stop 5-11.

${ }^{2}$ Aerospace Research Engineer, Turbomachinery and Heat Transfer Branch, 21000 Brookpark Rd., Mail Stop 5-11, AIAA Member.

${ }^{3}$ Aerospace Research Engineer, Turbomachinery and Heat Transfer Branch, 21000 Brookpark Rd., Mail Stop VPL-3, AIAA Associate Fellow.
} 


\section{Introduction}

$\mathrm{T}$ HE proliferation of CFD modeling for the design and analysis of turbomachinery has increased the importance of experimental data sets that are needed for code and model validation. Detailed knowledge of experimental boundary conditions is critical for complete specification of the data set. The NASA Glenn Transonic Turbine Blade Cascade is a linear cascade facility that has been used for testing the aerodynamic and heat transfer performance of a wide range of turbine blade configurations. Its large scale has allowed for the acquisition of detailed flow field and surface heat transfer data.

These data are being used to validate CFD codes and models that have been developed specifically for turbomachinery applications. Turbulence and transition models are often the most significant source of prediction uncertainty. As is the case with all calculated flow parameters, boundary conditions are needed for all primary turbulence model variables. For most currently used two-equation turbulence models such as variations of the $k-\varepsilon$ or $k$ - $\omega$ models, two inlet parameters are needed, namely the turbulence kinetic energy, $k$, and variable characteristics of turbulence dissipation rate $\varepsilon$ or specific dissipation rate $\omega$. The objective of this paper is to report on recent inlet turbulence measurements that have been made in the NASA cascade facility so that they can be used for subsequent code and model validation efforts.

\section{Experimental setup}

A complete description of the current tunnel configuration has been reported in Reference 1, but will be discussed briefly here. Figure 1 shows the layout of the facility. The blades are mounted on a disk that can be rotated to accommodate blade row inlet flow angles ranging from $-16.8^{\circ}$ to $+78.6^{\circ}$ as measured from the blade axial direction. Blade designs are scaled 2-D extrusions with a span of 6.000 inches. Two different blade sets were used during these tests: a scaled rotor blade tip section of a GE Energy Efficient Engine (EEE) design, ${ }^{2,3}$ used only for the low inlet turbulence no-grid cases; and the Variable Speed Power Turbine (VSPT) design, ${ }^{4}$ that was used with the turbulence grid for the high inlet turbulence cases. The incidence angles that are presented apply to the take-off and cruise conditions for the VSPT project. ${ }^{5}$ The blades and their nominal inlet flow vectors are shown in Figure 2.

As shown in Figure 1, a turbulence grid was installed upstream of the blade row to generate high inlet turbulence flow and was removed for low inlet turbulence flow. The grid used upstream blowing to diminish the wakes from the grid. The grid was constructed of one inch square bars with upstream blowing from 1/8" holes on 1/2" centers. Horizontal bars (5 or 6 depending on inlet flow angle) spanned the entire 6 " cascade span and were located on 6" centers. One vertical bar extended from the lower board to the upper board and was located at midspan and its length varied with inlet flow angle. The open area of the grid was approximately $75 \%$.

Probe survey slots are located upstream and downstream of the blades, but only the slot labeled Station 0 in Figures 1 and 2 was used for the current study. The axial and streamwise distances between Station 0 and the blade row depended on the blade set used and the inlet flow angle of the cascade as listed in Table 1. Also listed in the table is the inlet boundary layer thickness measured at the survey plane. An actuator traversing system was used to position the probe at any measurement location within the survey slot. Measurements were taken at various pitch locations along the slot and at spanwise locations $z / s$ of $0.500,0.333,0.167$, and 0.042 relative to the 6.0 inch blade span. Data were acquired over a range of inlet Reynolds numbers, based on axial chord, from 123,000 to 685,000, for various blade sets.

Flow measurements were obtained using a single channel, constant temperature anemometry (CTA) "hotwire" system, acquired at a sampling rate of $92 \mathrm{kHz}$ for 7 seconds. A single wire probe was placed perpendicular to the mainstream tunnel flow in an actuator that was mounted in the survey slot upstream of the blade row leading edge, upstream of blades 4 and 5. Configuration of the hotwire probe and acquisition of the voltage signals were performed using commercial software, with the raw data stored on a computer for analysis. Since the density of the flow inside the tunnel was low, calibration of the hotwire probe was performed in the tunnel by varying the tunnel pressure and thus the density and Reynolds number. In order to determine turbulence decay upstream of the cascade, measurements for the high turbulence data were also taken from a discrete access port in the tunnel wall upstream of the probe slot; for the low turbulence data when the grid was removed, one of the grid access holes was used as the discrete port because the streamwise turbulence decay would otherwise be too small to measure. Only spanwise measurements were possible from this location, and data were only acquired at $z / s=0.500$. The streamwise distance between this discrete port and the probe slot varied depending on the inlet flow angle of the cascade, and is listed in Table 1.

Obtaining flow measurements from CTA is well documented in literature. ${ }^{6}$ In brief, a small voltage is applied to a small wire approximately $0.0254 \mathrm{~mm}$ in diameter and $5 \mathrm{~mm}$ long to reach a specific wire temperature. As air blows across the wire, the temperature is kept constant by changing the voltage applied to it. By calibrating the wire 

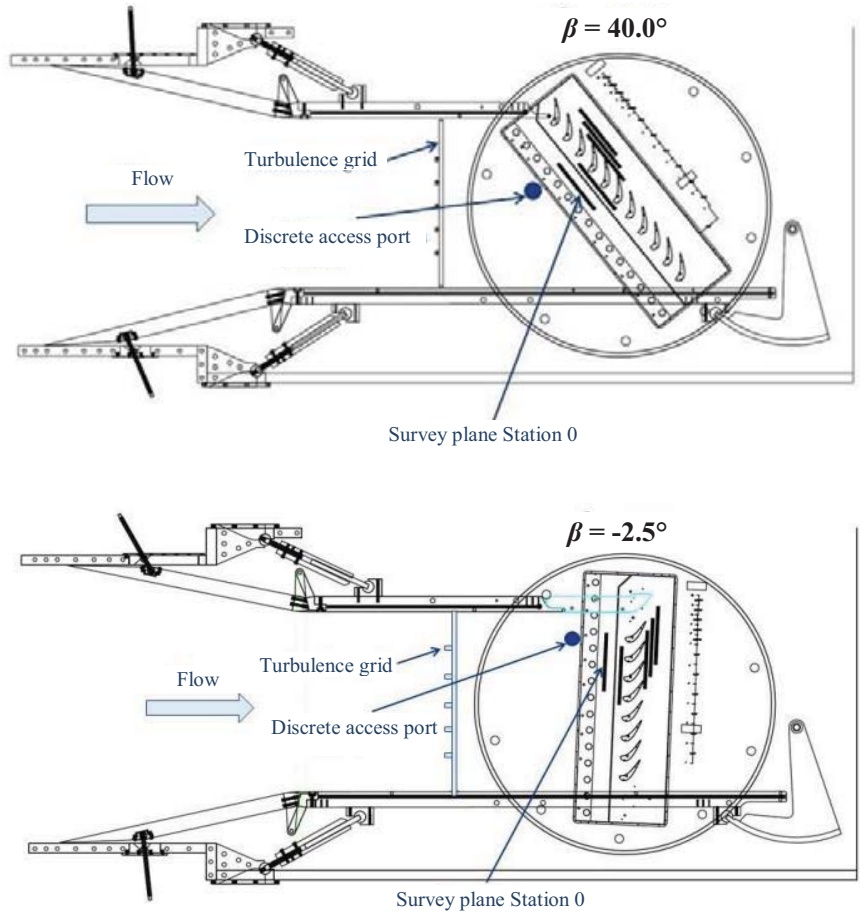

Figure 1. NASA Glenn Transonic Turbine Blade Cascade facility diagram.

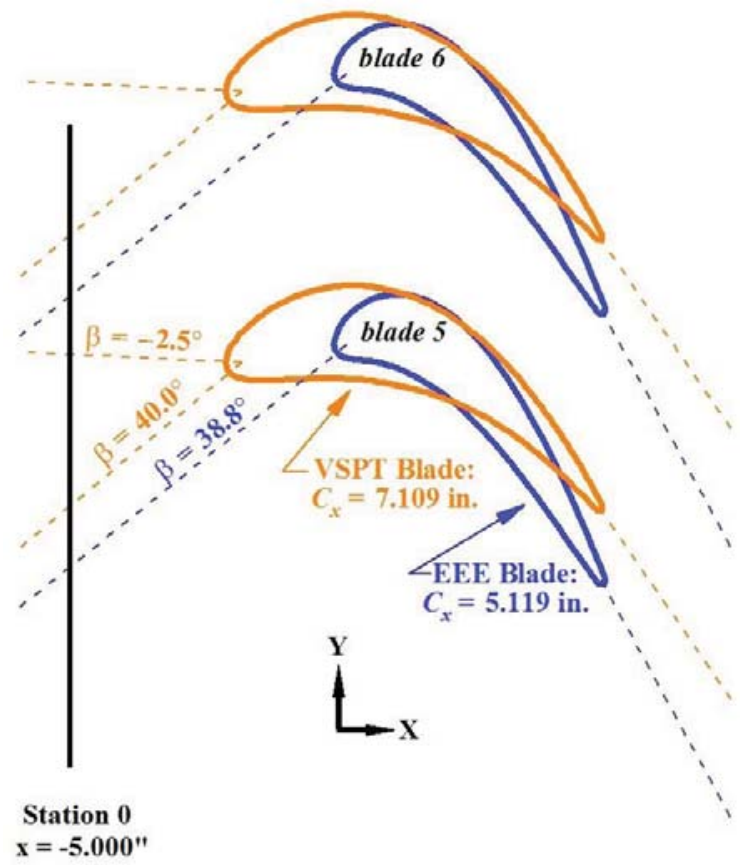

Figure 2. Inlet flow vectors for EEE and VSPT blades and position relative to survey plane

American Institute of Aeronautics and Astronautics 


\begin{tabular}{|c|c|c|c|c|c|c|c|c|c|}
\hline Case \# & $\begin{array}{c}\text { Blade } \\
\text { Type }\end{array}$ & $\begin{array}{c}\text { Turbulence } \\
\text { grid } \\
\text { installed? }\end{array}$ & $\begin{array}{c}\text { Inlet flow } \\
\text { angle } \beta \\
\text { with respect } \\
\text { to axial } \\
{[\mathrm{deg}]}\end{array}$ & $\begin{array}{c}\text { Inlet } \\
\text { Mach } \\
\text { number }\end{array}$ & $\begin{array}{c}\text { Inlet } \\
\text { Reynolds } \\
\text { number } \\
(\mathrm{Re})\end{array}$ & $\begin{array}{c}\delta_{99} \\
{[\mathrm{inch}]}\end{array}$ & $\begin{array}{c}\text { Streamwise } \\
\text { distance } \\
\text { between } \\
\text { discrete port } \\
\text { and survey } \\
\text { plane [inch] }\end{array}$ & $\begin{array}{c}\text { Axial distance } \\
\text { between } \\
\text { survey plane } \\
\text { and blade row } \\
\text { leading edge } \\
\text { [inch] }\end{array}$ & $\begin{array}{c}\Delta \text { Tu } \\
{[\%]}\end{array}$ \\
\hline 1 & EEE & No & 38.8 & 0.335 & 685,000 & 1.27 & 34.82 & 5.0 & 0.1 \\
\hline 2 & EEE & No & 38.8 & 0.335 & 342,000 & 1.40 & 34.82 & 5.0 & 0.1 \\
\hline 3 & VSPT & Yes & 40.0 & 0.435 & 370,000 & 0.73 & 10.001 & 2.95 & 7.4 \\
\hline 4 & VSPT & Yes & 40.0 & 0.250 & 395,000 & 0.72 & 10.001 & 2.95 & 4.5 \\
\hline 5 & VSPT & Yes & 40.0 & 0.250 & 155,000 & 0.82 & 10.001 & 2.95 & 4.1 \\
\hline 6 & VSPT & Yes & -2.5 & 0.192 & 123,000 & 0.85 & 7.668 & 2.95 & 2.2 \\
\hline 7 & VSPT & Yes & -2.5 & 0.196 & 308,000 & 0.75 & 7.668 & 2.95 & 2.0 \\
\hline 8 & VSPT & Yes & -2.5 & 0.311 & 284,000 & 0.76 & 7.668 & 2.95 & 2.0 \\
\hline
\end{tabular}

Table 1. Tunnel conditions

voltage with the product of the flow density and velocity, the tunnel flow velocity can be determined using a fourthorder polynomial. In addition, the fluctuations in the wire voltage can provide information on turbulence intensity and length scale. It should be noted that a single wire probe can only provide the one component of velocity perpendicular to the wire. One could measure the other velocity components by using multiple wires simultaneously (2- and 3-wire probes) and calibrating the probes at different angles. Due to the symmetry of the tunnel, the $V$ - and $W$-components of velocity are considered negligible as compared to the streamwise $U$-component along the centerline of the tunnel.

The plane of the upstream measurement Station 0 also has a line of surface static pressure taps and several midspan total pressure/total temperature Kiel probes. The Kiel probes are located just outside the passages of interest to avoid interfering with the hot wire probe. This facility instrumentation was used to set the cascade inlet conditions and to use for in situ calibration of hot wire probes.

The uncertainty in the hotwire velocity fluctuations and turbulence measurements depends on several factors, such as calibration, probe type, orientation, and flow angles. ${ }^{6,7}$ The measurement uncertainty for these experiments was calculated to be less than $2 \%$, assuming no probe interference and that the tunnel flow was streamwise only (only the $U$-component of velocity; no $V$ - or $W$ - components).

\section{Results}

Mean velocity, turbulence intensity, and integral length scale were calculated for various incidence angles and tunnel flow conditions, with and without a turbulence generating grid. Calculation of the inlet flow conditions involved first converting the hotwire voltages to velocity using the calibration data for the probe. The velocity signal can then be transformed to the frequency domain using a Fast Fourier Transform (FFT), which is then used to calculate the energy density spectrum. A sample of the spectral data at an inlet flow angle $\beta=-2.5^{\circ}$ is shown in Figure 3, which shows the amplitude spectrum of the streamwise velocity FFT (excluding the first point that contains the mean velocity) and the energy density spectrum with its relation to the Kolmogorov $-5 / 3$ inertial subrange spectral slope.

Turbulence intensity, integral length scale, and dissipation length scale were calculated using the following equations:

$$
\begin{aligned}
& T u=\frac{\bar{u}}{U} * 100 \% \\
& \Lambda=\left[\frac{E(f) U}{4 \overline{u^{2}}}\right]_{f \rightarrow 0}
\end{aligned}
$$




$$
\frac{1}{\lambda^{2}}=\frac{2 \pi^{2}}{U^{2} \overline{u^{2}}} \int_{0}^{\infty} f^{2} E(f) d f
$$

where $E(f)$ is the energy spectrum in the frequency domain. The integral length scale, $\Lambda$ (macro-scale), is a measure of the largest eddy size in the turbulent fluid. ${ }^{8}$ The dissipation length scale, $\lambda$ (micro-scale), is a measure of the average dimension of the eddies responsible for the dissipation of turbulent energy. ${ }^{8}$

The turbulence decay was measured between the upstream discrete port and the downstream location in the survey plane that matched the discrete port streamline location. As noted earlier, the distance between these two locations varied depending on the incidence angle of the blade row. The measurements at these two axial locations may be used to specify both $k$ and the length scale or dissipation rate at the inlet boundary when using turbulence models in CFD. This is achieved by using the upstream location value of $k$ to specify in the code and iteratively vary the length scale or dissipation rate at the inlet in order to match the downstream $k$ value, thus specifying both of the variables based on experimental data.

The inlet flow measurements are shown in Figures 4 - 7. Measurements were taken along the survey plane at different span locations and at various tunnel flow rates. The different tunnel flow rates for each case correspond to the design and off-design conditions that are expected for each flow angle and are shown in Table 1. The pitchwise location of the discrete upstream measurement changed as the blade row was rotated, and data at this location was taken only at $z / s=0.5$. For the no-grid data $\left(\beta=38.8^{\circ}\right)$, four spanwise locations of $z / s=0.50,0.33,0.17$, and 0.04 were measured along the survey plane and are plotted separately. For the other two flow angles $\left(\beta=40.0^{\circ}\right.$ and $\left.-2.5^{\circ}\right)$

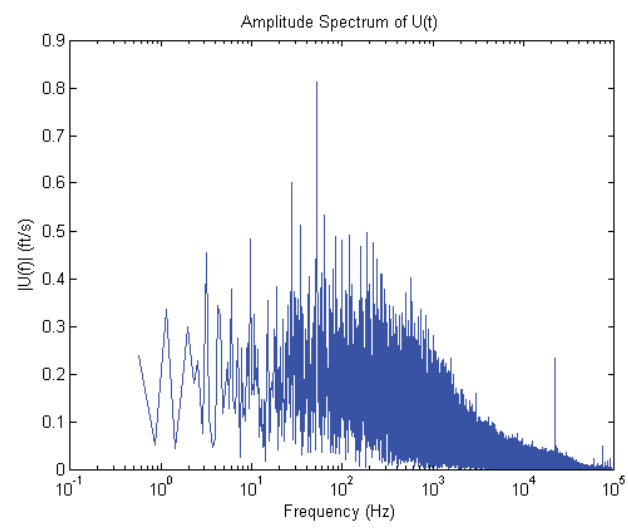

a)

Figure 3. Typical spectral measurements

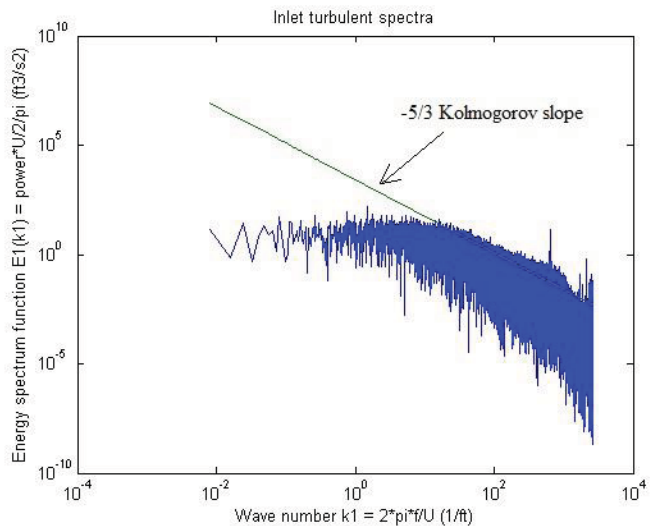

b)

in which the turbulence grid was installed, three spanwise locations of $z / s=0.50,0.33$, and 0.17 were measured along the survey plane and are not labeled separately but are grouped together for each case. As reported in Reference 2, the inlet turbulence grid significantly reduced the thickness of the inlet boundary layer, so the spanwise variation is not as great with the turbulence grid installed. The boundary layer thickness at the survey plane for each case is shown in Table 1.

Figure 4 shows the mean streamwise velocity measurements normalized by the averaged calculated tunnel velocity $U_{\infty}$. Values greater than one can occur because the average tunnel velocity was used to calculate the normalized velocity. The distance between the survey plane and the blade row varied depending on the blade set used. For the EEE blade, this distance was $97.7 \%$ of the blade axial chord length; for the VSPT blade, it was $41.5 \%$. Even though the survey plane seems to be far enough upstream, there appears to be some effect from the blades downstream. Bumps in the data occur near the approximate locations of the leading edge of the blades, at the pitchwise locations $Y / p=-1.9,-0.9$, and 0.1 , and become more pronounced as the blade row rotates to a vertical orientation in the tunnel. The mean velocity along the survey plane is nearly constant for all the cases. For the nogrid case, there is a slight decrease in velocity at the pitchwise location $Y / p=1.0$ near the tunnel endwall at the spanwise locations $z / s=0.17$ and 0.04 . With the turbulence grid installed, there is some slight scatter in the data in the spanwise direction, especially at $\beta=40^{\circ}$.

The inlet turbulence intensity measurements are shown in Figure 5. For the no-grid case, turbulence intensity does not seem to be affected by the blade row being at an angle and is nearly constant at $0.3 \%$, except for $z / s=0.17$ and 0.04 near the tunnel endwall which have higher intensity values. With the turbulence grid installed, the 


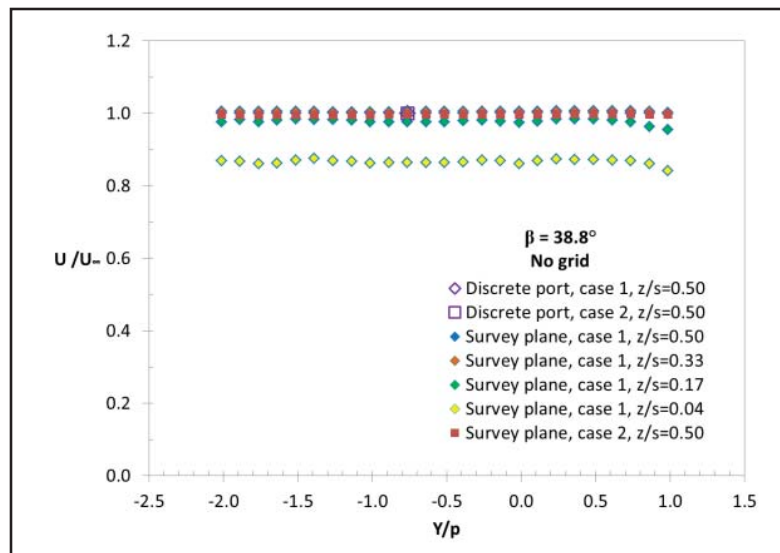

(a)

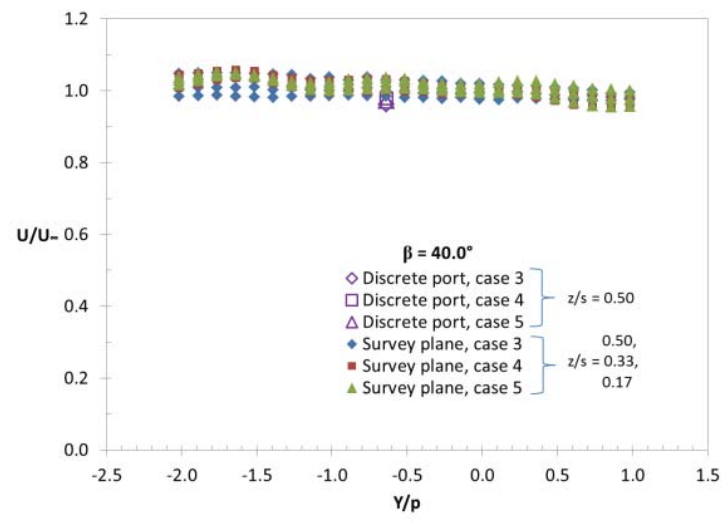

(b)

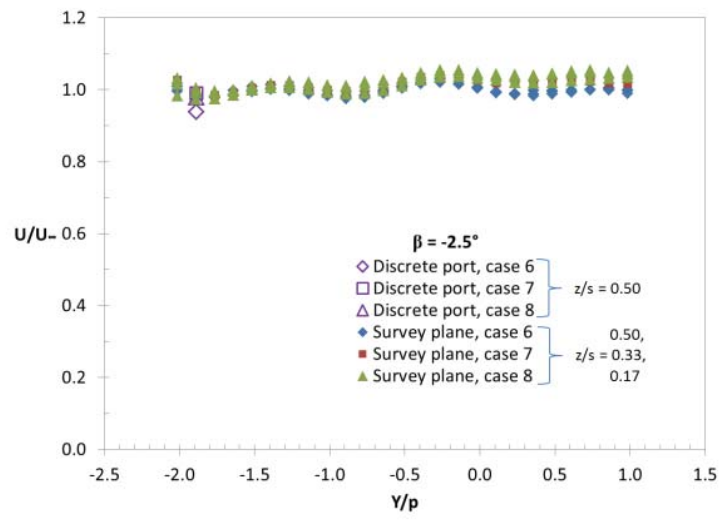

(c)

\section{Figure 4. Inlet tunnel mean velocity measurements.}

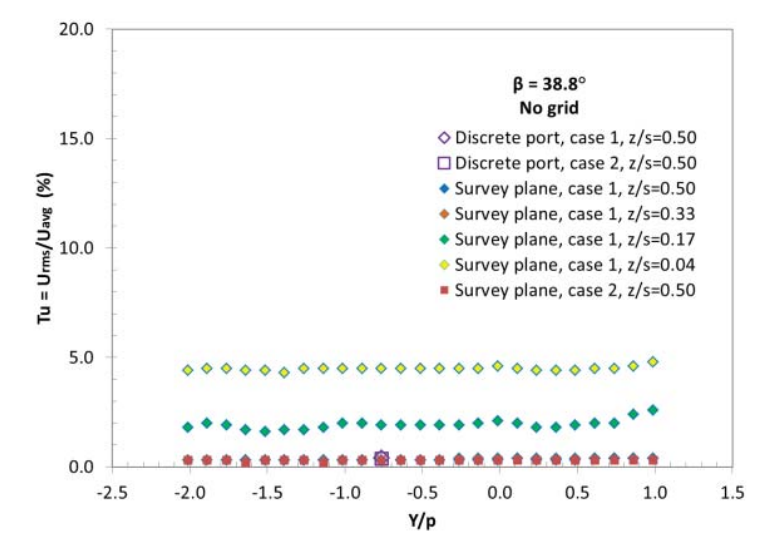

(a)

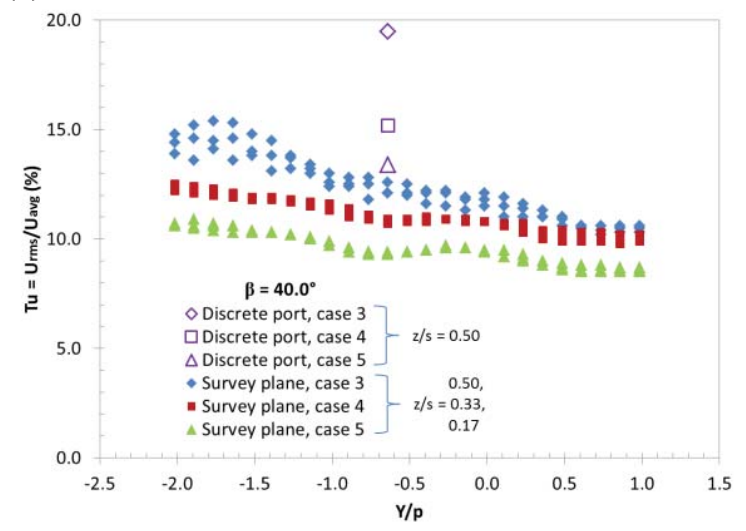

(b)

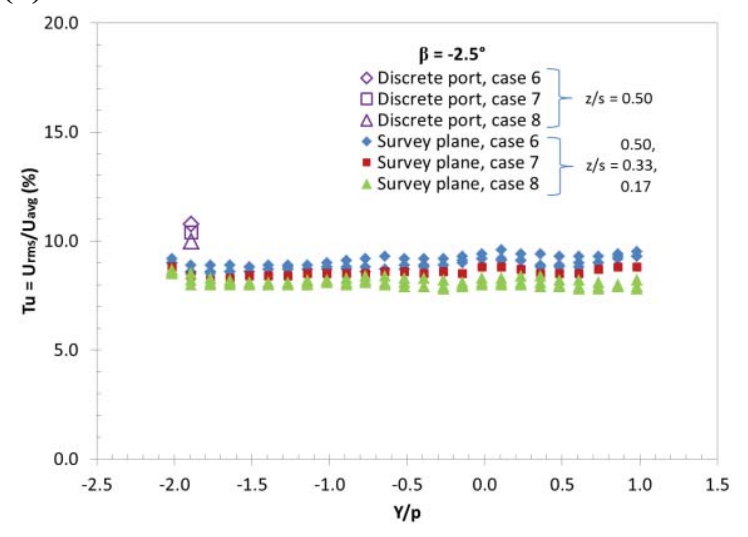

(c)

Figure 5. Inlet turbulence measurements.

turbulence intensity varies along the survey plane since the blade row is at an angle, and each blade will experience a slightly different turbulence level. The turbulence intensity measurements shown in Figures $5 \mathrm{~b}$ and $5 \mathrm{c}$ agree well with a correlation from Baines and Peterson ${ }^{9}$ for the one inch square bar grid used in the current study. At $\beta=40.0^{\circ}$, there is little scatter in the spanwise direction for cases 4 and 5. Case 3 has a higher inlet Mach number, and its turbulence intensity levels are higher and have more scatter in the spanwise direction. The effects from the blades downstream of the survey plane are evident at this inlet flow angle. At $\beta=-2.5^{\circ}$, turbulence intensity does not vary as much in the survey plane since the blade row is more vertical, and there is less scatter in the spanwise direction for all three cases. The turbulence decay between the upstream discrete port and the associated streamline location in the survey plane for each case is listed in Table 1. 


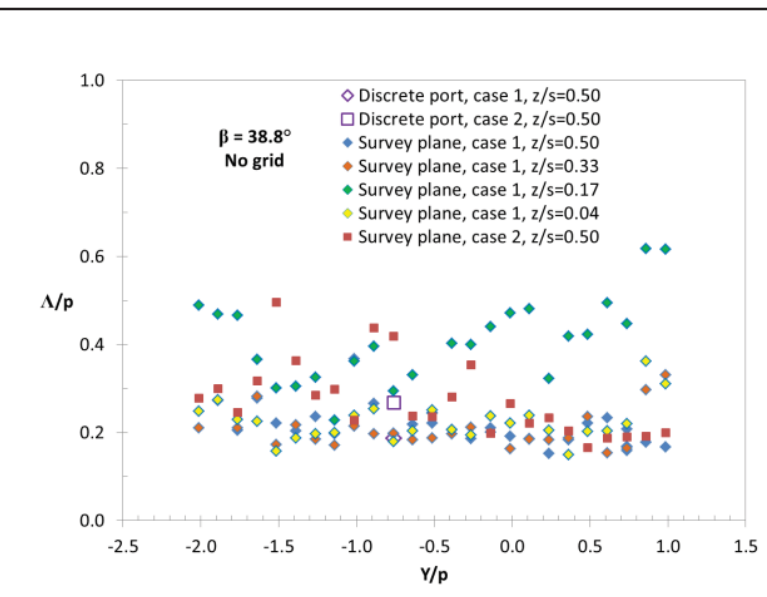

(a)

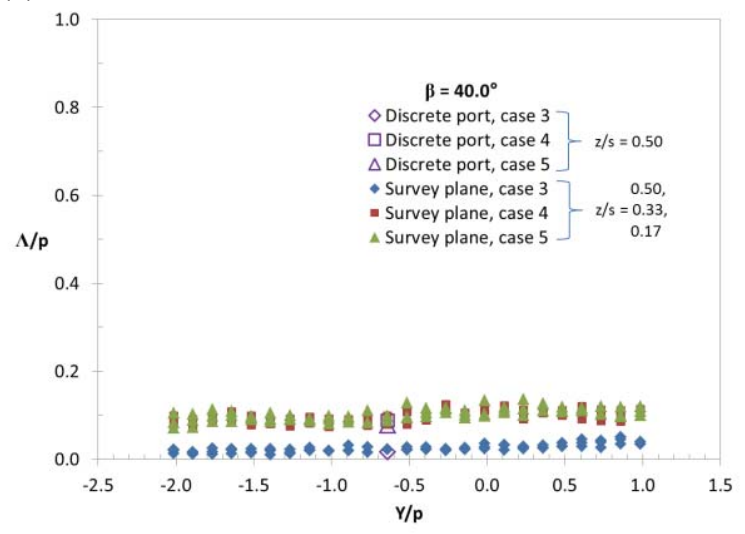

(b)

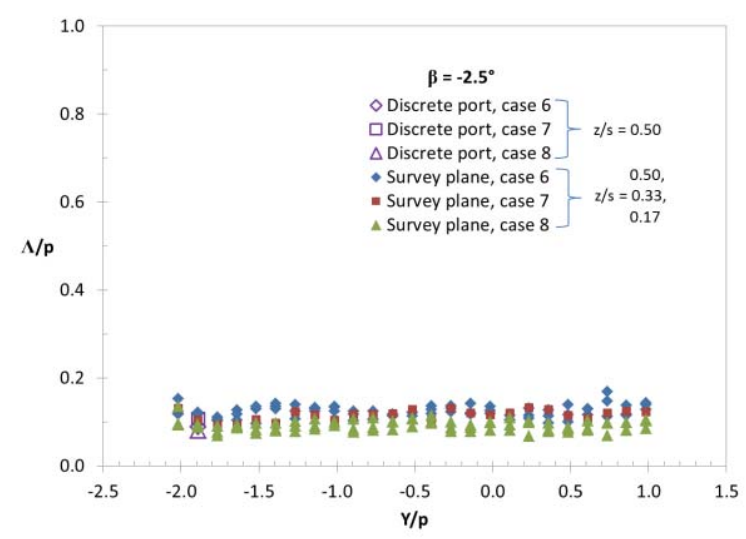

(c)

Figure 6. Integral length scale measurements.

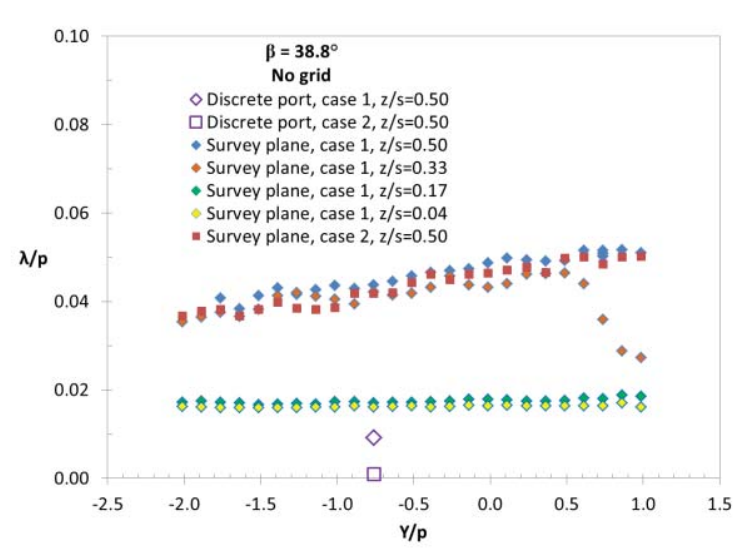

(a)

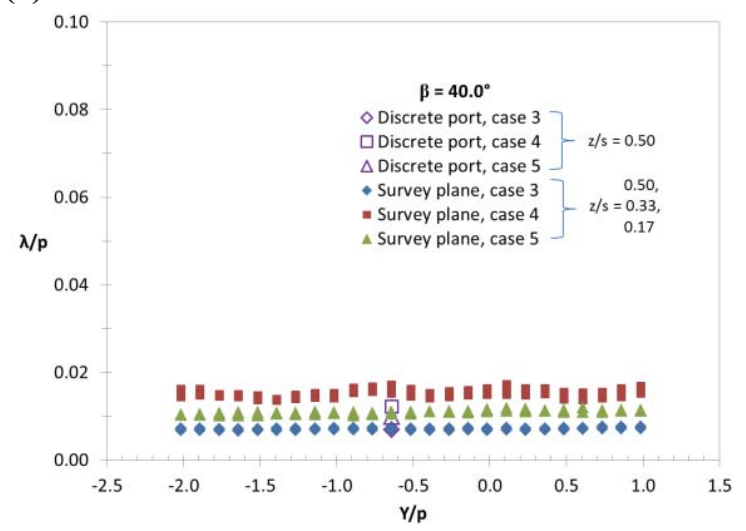

(b)

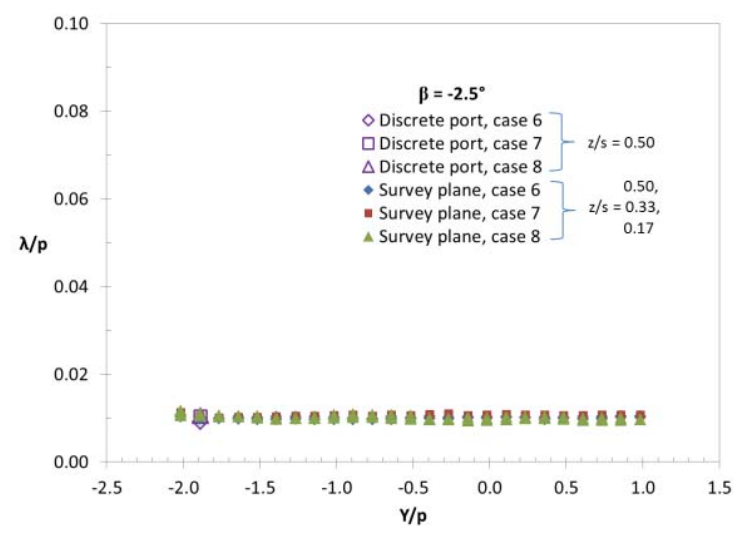

(c)

Figure 7. Dissipation length scale measurements.

The integral length scale measurements are shown in Figure 6 and are normalized by the blade pitch. For the nogrid case, this macro-scale is fairly constant at about 0.2 along the survey plane for case 1 , except for $z / s=0.17$, where there is more scatter in the data probably due to being near the edge of the boundary layer. For case 2, there is more scatter for $Y / p<0$, with length scale values ranging from 0.2 to 0.4 , whereas for $Y / p>0$, values level out to a nominal value of 0.2 . With the turbulence grid installed, the integral length scale along the survey plane is mostly constant. At $\beta=40.0^{\circ}$, there appears to be little variation in the spanwise direction. Case 3 , with the higher inlet 
Mach number of 0.435 , has a smaller length scale of about 0.03 , while cases 4 and 5 at a Mach number of 0.25 have essentially the same length scale of nominally 0.1 . At $\beta=-2.5^{\circ}$, the integral length scale is nearly the same for all three cases, but there is more scatter in the spanwise data, with values ranging from about 0.05 to 0.15 .

The dissipation length scale normalized by pitch is shown in Figure 7. This micro-scale is roughly one-tenth the integral length scale for all cases. For the no grid case of Figure 7a, the dissipation scale is affected by the blade row orientation, as is seen by the slope of the data along the survey plane at $z / s=0.50$ and 0.33 . However near the tunnel endwall, the length scale is nearly constant with a nominal value of 0.018 . It is not understood why the $z / s=0.33$ case starts to drop at the higher pitch, but a similar effect is seen in Figure 6a, with the integral length scale starting to increase near the same location. With the turbulence grid installed, the dissipation length scale is nearly constant along the survey plane for each case, with little variation in the spanwise direction. At $\beta=40.0^{\circ}$, the effects of the blades downstream can be seen for case 4 . At $\beta=-2.5^{\circ}$, the length scale is nearly constant at 0.01 for all three cases.

\section{Conclusion}

Inlet flow measurements were obtained using constant temperature "hotwire" anemometry surveys upstream of a linear cascade blade row. Data were shown for tunnel flow with and without a turbulence grid installed. Turbulence intensity, decay, and integral and dissipation length scales were measured for flow conditions corresponding to various conditions that the VSPT and EEE blade designs would experience at specific flow angles. These data will help better understand the flow physics and can aid in validating CFD codes and heat transfer for the VSPT blade cascade.

\section{Acknowledgments}

This work is supported under the NASA Fundamental Aeronautics Program, Subsonic Rotary Wing Project.

\section{References}

${ }^{1}$ Flegel-McVetta, A., Giel, P., Welch, G., “Aerodynamic Measurements of a Variable-Speed Power-Turbine Blade Section in a Transonic Turbine Cascade at Low Inlet Turbulence", NASA/TM-2013-218069.

${ }^{2}$ McVetta, A., Giel, P., Welch, G., "Aerodynamic Investigation of Incidence Angle Effects in a Large Scale Transonic Turbine Cascade," AIAA 2012-3879, presented at the 48th AIAA Joint Propulsion Conference, Atlanta, Georgia, Jul. 30-Aug. 1, 2012.

${ }^{3}$ Timko, L. P., Energy Efficient Engine High Pressure Turbine Component Test Performance Report, NASA/CR-1984$168289,1984$.

${ }^{4}$ Ford, A, Bloxham, M., Turner, E., Clemens, E. and Gegg, S., "Design Optimization of Incidence-Tolerant Blading Relevant to Large Civil Tilt-Rotor Power Turbine Applications," NASA/CR-2012-217016, Dec. 2012.

${ }^{5}$ Flegel, Ashlie B., Giel, Paul W., Welch, Gerard E., 2014, “Aerodynamic Effects of High Turbulence Intensity on a VariableSpeed Power-Turbine Blade with Large Incidence and Reynolds Number Variations," to be presented at the $50^{\text {th }}$ AIAA/ASME/SAE/ASEE Joint Propulsion Conference, Cleveland, Ohio, July 2014.

${ }^{6}$ Bruun, H.H., 1995, "Hot-Wire Anemometry Principles and Signal Analysis," Oxford University Press: Oxford, UK.

${ }^{7}$ Yavuzkurt, S., 1984, “A Guide to Uncertainty Analysis of Hot-Wire Data," Journal of Fluids Engineering, Vol. 106, pp. 181-186.

${ }^{8}$ Roach, P.E., 1986, "The generation of nearly isotropic turbulence by means of grids," Heat and Fluid Flow, Vol. 8, No. 2, pp 82-92.

${ }^{9}$ Baines, W.D., and Peterson, E.U., "An lnvestigation of Flow Through Screens," Transitions of the ASME, Vol. 73, No. 5, July 1951. 